\title{
Metrological intercomparison of terrestrial laser scanning systems
}

H.. González-Jorge ${ }^{1^{*}}$, P. Rodríguez-Gonzálvez ${ }^{2,3}$, Y. Shen ${ }^{4}$, S. Lagüela ${ }^{2}$, L. Díaz-Vilariño ${ }^{1}$, R. Lindenbergh $^{4}$, D. González-Aguilera ${ }^{2}$, P. Arias $^{1}$

${ }^{1}$ Geotech Group, Galician Aerospace Innovation Center (CINAE), University of Vigo, School of Mining and Energy Engineering, 36310, Vigo, Spain.

${ }^{2}$ Department of Cartographic and Land Engineering, University of Salamanca, Polytechnic School of Avila,Hornos Caleros 50, 05003 Avila, Spain.

${ }^{3}$ Department of Mining Technology, Topography and Structures, University of Leon, Avda. Astorga s/n, 24401 Ponferrada, Spain.

${ }^{4}$ Dept. of Geoscience and Remote Sensing, Delft University of Technology, Stevinweg 1, 2628 CN Delft, The Netherlands

*Corresponding author: higiniog@uvigo.es; phone: +34 986818752

\begin{abstract}
Intercomparison among six terrestrial laser scanner systems focused on the measurement of small elements $(<0.5 \mathrm{~m})$ is performed. Two standard artifacts containing 3D printing spheres and steps of variable height are used for the experiment. Results show errors between -4.5 $\mathrm{mm}$ and $3.5 \mathrm{~mm}$ in the measurement of distance between sphere centers and errors ranging from $-1 \mathrm{~mm}$ to $8 \mathrm{~mm}$ in the measurement of distances between step planes. The most stable systems for measuring small elements seem the Leica C10, Faro Photon and Riegl LMS Z390i.
\end{abstract}

Keywords: measurement standards, instrumentation, geometry 


\section{Introduction.}

Metrology, the science of measurement, considers the theoretical and practical aspects of measurements. One key factor in determining the quality of different measurement systems is conducting regular metrological intercomparisons. Intercomparisons consist on the organization, development and evaluation of similar samples by several laboratories and systems, in accordance with pre-established conditions. The objective of intercomparisons is focused on demonstrating the technical competence of the different sensors and measurement procedures under normal conditions. All intercomparisons should be planned and carried out carefully in order to maintain an adequate and uniform quality level of measurement of each metrological variable $[1,2]$.

Terrestrial laser scanning (TLS) systems have emerged as useful surface measuring devices during the last years. Applications are found in areas such as civil engineering [3], architecture [4], mining [5], forestry [6] and cultural heritage [7]. The measurement principle of terrestrial laser scanning is based on time of flight (ToF) or phase shift (PS) laser ranging and optical encoders to determine zenithal and azimuthal angles. Their development has been accompanied by advances in the optoelectronics industry and computers science. Improvements in optoelectronics provide weight decrease, longer range, higher accuracy and higher spatial resolution. Improvements in computer science contribute to data visualization and data processing. Terrestrial laser scanning provides Cartesian coordinates calculated from a spherical coordinate system. They are visualized as point clouds [8] that can include additional attributes as the intensity of the reflected signal and RGB color information from integrated cameras. These systems provide high geometric detail over medium range areas. Scan alignment, also called registration, is common when large area coverage is required or occlusions are present in the survey [9]. The increase of computer capabilities allows the management of large point clouds, typically consisting of several millions of points.

Despite the importance of TLS systems, their evaluation through metrological studies is not common and authors typically focus on applications of the technology. First research in this area tested spatial resolution and accuracy of point clouds, focusing on the development of mathematical models to describe the systematic errors by establishing a parallelism with total stations $[10,11,12]$. Based on these calibration models the accuracy of the systems could be improved by $30-40 \%$. Other authors exploit the similarities between panoramic cameras 
and TLS systems [13]. The spatial resolution of terrestrial LiDAR is investigated by several researchers for determining the maximum level of detail. It was found that the resolution is defined by the contribution of two main factors: the sampling interval and the beam width of the laser ray [14]. Boehler et al. [15] studied the angular accuracy, range noise, resolution and the effects of surface reflectivity. They concluded that errors increase with range. Angular accuracy was determined by comparing the distance between the centers of two spheres. Gordon et al. [16] developed a set of experiments to quantify the precision and accuracy of laser scanners. Soudarissanane et al. [17] describe how both increasing range and incidence angle affect the noise level of TLS data. Mechelke et al. [18] compared the accuracy, range noise, the influence of color on range measurements and the so-called level compensator accuracy for a set of TLS systems (Trimble GX, Mensi GS100/200, Leica ScanStation, Z+F Imager 5006 and Faro LS880 HE. González-Jorge et al. [19] compared the Riegl LMS Z390i and Trimble GX systems using a physical artifact consisting of five Delrin spheres equidistantly assembled on an aluminum block and seven aluminum cubes of different dimensions. Spheres enable the metrological comparison to results obtained by more accurate technologies, such as coordinate measuring machines. Such physical artefacts were also successfully used for the metrological characterization of mobile laser scanning measurements [20] and measurements obtained by gaming laser scanning sensors [21 - 23].

The above review shows that, to the best of our knowledge, there are no recent intercomparisons that collected information on a significant number of different TLS systems. Typically, most laboratories only have one or two TLS systems. Consequently, it is complicated to work with many systems in one experiment. In addition, physical artifacts and measurement procedures are not normalized by metrological standardization bodies.

To tackle this issue, this work presents a methodology that makes it feasible to perform a valid comparison between measurements obtained at completely different laboratories. Application of the proposed procedure allows us to present an intercomparison of six different TLS systems (Faro Focus 330X, Riegl LMS Z390i, Faro Photon 80, Trimble GX, Faro Focus 3D and Leica C10 ScanStation) operated at three different laboratories (University of Vigo and University of Salamanca in Spain and TU Delft in The Netherlands). The handicap of the different locations of the laboratories and instruments is solved using two portable standard artifacts. Their main components are manufactured using a 3D printing machine to keep costs low and to make the artifacts reproducible for other users. The measurement procedure is 
standardized by a measurement protocol provided by the University of Vigo. The remaining of this manuscript is organized as follows: Section 2 describes the hardware, i.e. the characteristics of the different TLS under study and the physical artifacts. Section 3 introduces the measurement procedure, Section 4 deals with the results and discussion. Finally, section 5 exhibits the conclusions.

\section{Materials.}

\subsection{Terrestrial LiDAR systems}

Six different terrestrial LiDAR systems owned by three different laboratories are used for the intercomparison. The technical specifications depicted in Table 1 are obtained from the datasheets provided by the manufacturers [24-29].

The maximum scan range is provided by the Riegl LMS Z309i scanner (400 m), while the minimum range is given by the Faro Photon $80(76 \mathrm{~m})$. The Faro Focus $330 \mathrm{X}$ and Faro Focus 3D exhibit the maximum pulse repetition rate at 976,000 points/s. The Trimble GX depicts the slowest one $(5,000$ points/s). TLS errors in the range measurement depend partly on the measurement principle. ToF instruments present more stable error values up to ranges of $50 \mathrm{~m}$ according to datasheets provided by manufacturers. The error increases with distances above $25 \mathrm{~m}$ in the case of the PS scanners, i.e. the three Faro TLS. Reported range errors are between $2 \mathrm{~mm}$ for the three Faro systems to $7 \mathrm{~mm}$ for the Trimble GX. Regarding the laser wavelength, the Trimble GX and the Leica C10 operate in the visible range of the electromagnetic spectrum, while the other systems belong to the infrared. The reported divergence of the laser beam is around $0.01^{\circ}$ for all systems. However, the Trimble GX and the Leica $\mathrm{C} 10$ do not provide data on laser beam divergence.

All the systems have a horizontal field of view of $360^{\circ}$. With regard to the vertical field of view, it ranges between $60^{\circ}$ for the Trimble GX and $320^{\circ}$ for the Faro Photon 80 . The step width for vertical angles ranges from $0.0003^{\circ}$ (Trimble GX and Leica C10) to $0.009^{\circ}$ (Faro Focus 330X, Faro Photon 80, Faro Focus 3D). On the other hand, horizontal angle increments are between $0.0003^{\circ}$ (Leica C10) and $0.009^{\circ}$ (Faro Focus 330X and Faro Focus 3D). The Riegl LMS Z390i is the heaviest scanner, while the Faro Focus 3D has the lowest weight.

\subsection{Standard artifacts.}


Two different standard artifacts were developed for the intercomparison. They are designed to be easy to manufacture in a laboratory at low cost. They showed robustness and reliability during all experiments without physical damages in spite of traveling among laboratories.

The first physical artifact consist of two spheres of $0.15 \mathrm{~m}$ of nominal diameter separated by $0.5 \mathrm{~m}$ of nominal distance between the sphere centers. The spheres are manufactured using a BQ Witbox 3D printing machine [30]. They are glued and screwed to an aluminum bar. The bar is mechanized for easy assembly to a topographic tripod. Fig. 1 shows an image of the artifact. This standard was used instead of other previously developed in the Laboratory at Unviersity of Vigo [8] to decrease the weight and make it more portable.

The second physical artifact (Fig. 2) consists of a set of steps separated by different nominal step heights as depicted in Table 2. This artifact is also manufactured using the BQ Witbox $3 \mathrm{D}$ printing machine.

The main material in both cases is the polylactic acid (PLA), a common thermoplastic polymer obtained from the filament of the $3 \mathrm{D}$ printing machine. Aluminum used in the sphere standard does not act as measuring surface. PLA surfaces show enough diffusive behavior to laser light and do not provide spurious reflections that could affect to LiDAR measurement. Surface coating of raw materials is not required.

After production, the standard artifacts were calibrated using an articulated coordinate measuring machine (ACMM), the Hexagon Metrology Absolute Arm 7325SI [31]. Its technical specifications are given in Table 3.

\section{Methods.}

An indoor intercomparison procedure is developed by the University of Vigo and provided to the other laboratories. Authors recommend indoor measurements since it is easier to establish controlled environmental conditions (temperature, relative humidity, and pressure) that affect to air refractive index and to range measurements. The aim is to standardize data collection as performed at each of the three laboratories, which consecutively makes it possible to reliably compare the measurements as obtained at each location. The procedure is summarized below.

\subsection{Physical artifact based on spheres.}

a. Place the artifact horizontally on a topographic tripod. 
b. Scan the spheres at maximal scanner resolution at $10 \mathrm{~m}, 20 \mathrm{~m}, 30 \mathrm{~m}, 40 \mathrm{~m}$ and $50 \mathrm{~m}$ range. Each laboratory is free to use the range measuring method they prefers (i.e. measuring tape, electronic distance measurement). The nominal distance value between the standard artifact and the TLS does not require millimeter accuracy. The quality factor should be selected to the maximum value in all cases where the scanner allow this configuration as occurs with the Faro Focus scanners. This fact allows to repeat a number of measurements from the same position and average them to obtain a more accurate result. A maximum range of $50 \mathrm{~m}$ is considered to achieve enough resolution and accuracy of the systems and allow an enough number of points to perform the comparison. In addition, this allows to adapt to the geometric conditions of the corridors available in the different laboratories where the experiments have been carried out.

c. Use Cloud Compare software [32] to fit a sphere to both artifact spheres as sampled by the point cloud. Fig. 3 shows an example of a sphere fit to point cloud data obtained by a Riegl LMS Z390i scanner at the University of Vigo. The point cloud is cropped avoiding the noisy points from the border of the elements

d. Determine the distance between the sphere centers.

e. Repeat the experiment placing the artifact vertically.

f. Report results in the Excel worksheet for the intercomparison.

\subsection{Physical artifact based on step heights.}

a. Place the artifact on a topographic tripod. Orient the artifact to guarantee sufficiently dense sampling of the horizontal planes $\mathrm{H}$.

b. Scan the artifact at maximum scanner resolution at $10 \mathrm{~m}$ range. Only one range is used since ranges larger than $10 \mathrm{~m}$ in general do not provide data that enables to distinguish between closest planes. Each laboratory is free to use the measuring method they prefers. The nominal distance value between the standard artifact and the TLS does not require millimeter accuracy. The quality factor should be selected to the maximum value in all cases where the scanner allow this configuration as occurs with the Faro Focus scanners. This fact allows to repeat a number of measurements from the same position and average them to obtain a more accurate result. 
c. Use Cloud Compare software to fit planar models to the planar patches H1 to H5 in the point cloud (Fig. 4). The point cloud is cropped avoiding the noisy points from the border of the elements

d. Determine distances between the centroids of the planes.

e. Integrate the results in the Excel worksheet for the intercomparison.

\section{Results and discussion.}

Figs. 5 and 6 show the error in the evaluation of the distance between the center of the spheres versus the measurement range. The physical artifact is situated in horizontal position in Fig. 5 and in vertical position in Fig. 6. The error is calculated according to equation (1). The distance obtained from the ACMM acts as reference value. The centroid of the spheres is calculated using a Least Square Fitting Algorithm applied to a set of points sampling the surface of the sphere [8].

$\Delta D_{S}=D_{S H M}-D_{S L}$

where $\Delta D_{S}$ is the error in the evaluation of the distance between the center of spheres, $D_{S H M}$ is the distance obtained from the ACMM and $D_{S L}$ the distance obtained from each terrestrial laser scanner under study.

Sphere fitting is very robust in all cases. The procedure performs a manual selection of the sphere points from the point cloud to avoid outliers that typically appear on the edge of the sphere. In spite of this, close to one half of the sphere is selected for the fitting. Number of points for fitting are more than thirty in all cases. In addition, accuracy of sphere fitting show values better than $2 \mathrm{~mm}$.

Error ranges between $-4.5 \mathrm{~mm}$ and $2 \mathrm{~mm}$ in the horizontal position of the artifact and between $-3 \mathrm{~mm}$ and $3.5 \mathrm{~mm}$ in the vertical position of the artifact. No significant difference between the two cases (horizontal and vertical) is observed. It seems that the artifact orientation does not affect the error. This fact reveals correct behavior in both horizontal and vertical angular measurements and demonstrates the encoders that measure vertical and horizontal angles show similar quality in all TLS. Another important result is that there seems to be no trend in the error related to the measuring range. An increase would be expected although experimental data show that it is not the case. Range affects to inhomogeneity of atmospheric path travel of the laser ray that contributes to error. In this work, the use of indoor facilities 
and the high quality LiDAR systems that perform automatic self-calibration measuring environmental conditions results in no contribution of this type of error.

The Leica C10 scanner shows stable error values, especially on the horizontal measurements. Similar results are obtained from the Riegl LMS Z390i and Faro Photon 80 systems. Their error values range between $-2.5 \mathrm{~mm}$ and $1.5 \mathrm{~mm}$. Other systems, such as the Faro Focus $330 \mathrm{X}$, show larger error variations from $-3 \mathrm{~mm}$ to $3.5 \mathrm{~mm}$, which are outside the a-priori measurement range error at $68.27 \%$ confidence level (Table 1). The other systems show intermediate results. The variability in error is of great importance, because a stable error can be either anticipated in the measurement setup or more easily corrected if required. A variable error is difficult to correct and will inevitably cause problems in the measurements.

Fig. 7 shows the error in the evaluation of the distance between the horizontal planes of the standard artifact. The error is calculated as described in equation (2). The distance between the planes obtained from the ACMM acts as reference value. The planes are calculated using a Least Square Fitting Algorithm from a set of points sampling the plane [8]. The centroids from each plane are used as reference points for the calculation of the distance between planes.

$\Delta D_{P}=D_{P H M}-D_{P L}$

Here $\Delta D_{P}$ is the error in the evaluation of distances between the planes of the artifact, $D_{P H M}$ the distance obtained from the ACMM and $D_{P L}$ the distance obtained from each terrestrial laser scanner under study.

The resulting error approximately ranges between $-1 \mathrm{~mm}$ to $8 \mathrm{~mm}$ for the horizontal planes. Errors from the horizontal planes are increasing with the increase in distance between planes. It ranges between $1 \mathrm{~mm}$ and $2 \mathrm{~mm}$ for all scanners except Faro Focus 3D. This trend is an expected metrological result, where dimensional error increases with length. The Riegl LMS Z390i and Faro Photon 80 scanners show the lowest error for the $\mathrm{H}$ planes while the Faro Focus 3D exhibits the largest one, an increase of nearly $6 \mathrm{~mm}$.

It must be noted that results at $10 \mathrm{~m}$ range (Figs. 5 - 7) show lower error for the evaluation of the distance between the center of the spheres $(-2 \mathrm{~mm}$ to $1 \mathrm{~mm})$ than between the planes $(-1$ $\mathrm{mm}$ to $4 \mathrm{~mm}$ ). Quality of the point cloud is similar in both cases, so the result should be from the better fitting to the sphere primitive than to the plane primitive. 


\section{Conclusion.}

An intercomparison experiment for comparing terrestrial laser scanning systems situated at different locations has been developed. It focuses on the determination of the dimensions of small and portable elements $(<0.5 \mathrm{~m})$. The experiment is supported by the development of two standard artifacts previously calibrated using a measurement system with higher metrological capabilities than terrestrial laser scanners. 3D printing technology is used for manufacturing the standards. The standard artifacts and a specific measuring procedure are sent to the laboratories that participate in the intercomparison experiment. Six different scanners are used: Faro Focus 330X, Riegl LMS Z390i, Faro Photon 80, Trimble GX, Faro Focus 3D, and Leica C10. It should be noted that the results are based on the evaluation of one specific specimen of these scanner types. It would be interesting to validate in future if results are indeed stable for different specimens of the same scanner type.

Errors in the measurement of the standard artifact based on spheres are between $-4.5 \mathrm{~mm}$ and $2 \mathrm{~mm}$ in horizontal position and between $-3 \mathrm{~mm}$ and $3.5 \mathrm{~mm}$ in vertical position. The Leica C10, Riegl LMS Z390i, and Faro Photon show stable results that could be easily corrected if necessary. The Faro Focus 330X and Faro Focus 3D seem to show higher instabilities, while Trimble GX exhibits intermediate results. No trend appears in the error with the increase of range.

The error in the measurement of the standard artifact based on step height shows an increase with the distance between planes in all the scanners under study. The maximal increase in error of $6 \mathrm{~mm}$ seems to occur for the Faro Focus 3D. The Riegl LMS390i and Faro Photon scanners had errors that only increased by around $1 \mathrm{~mm}$, which were the lowest values found in the experiment.

Future trends will focus to extend the use of 3D printing technology in the development of new artifact standards for LiDAR measurements. Procedures and standards will also be extended to different type of photogrammetric systems.

\section{Acknowledgements}


Authors would like to thank to the Xunta de Galicia - Spain, for the financial support given through the grant (ED481B 2016/079-0, ED431C 2016-038) and to the Ministerio de Economía y Competitividad - Gobierno de España - Spain (TIN2016-77158-C4-1-R, PTQ13-06381).

\section{References}

[1] Stone, J. A.: "Methods for evaluating the reference value in laboratory intercomparisons of dimensional measurements", Proc. SPIE, 2005, 5879, pp. $1-8$.

[2] Bangen, S. G., Whaton, J. M., Bouwes, N., Bouwes, B. Jordan, C.: “A methodological intercomparisons of topographic survey techniques for characterizing waldeable streams", Geomorphology, 2014, 206, pp. $343-361$.

[3] Park, H. S., Lee, H. M. Adeli, H., Lee, I.: “A new approach for health monitoring of structures: Terrestrial laser scanning", Comput. Aided. Civ. Inf., 2007, 22(1), pp. 19 - 30.

[4] Tang, P., Huber, D., Akinci, B., Lipan, R., Lytle, A.: “Automatic reconstruction of as built building information models from laser scanned point clouds: A review of related techniques", Automat. Constr., 2010, 19(7), pp. 829 - 843.

[5] Lai,P., Samson, C.: “Applications of mesh parametrization and deformation for unwrapping 3D images of rock tunnels", TUST, 2016, 58(1), pp. 109 - 119.

[6]. Zhang, W., Chen, Y, Wang, H., Chen, M., Wang, X., Yan, G.: "Efficient registration of terrestrial LiDAR scans using a coarse to fine strategy for forestry applications", Agr. Forest Meteorol., 2016, 225, pp. 8 - 23.

[7] Georgopoulys, G. D., Telioni, E. C., Tsotzu, A.: “The contribution of laser scanning technology in the estimation of ancient Greek monuments", Surv. Rev., 2016, 48(349), pp. $303-308$.

[8] González-Jorge, H., Riveiro, B., Armesto, J., Arias, P: "Standard artifact for the geometric verification of terrestrial laser scanning systems”, Opt. Laser Technol., 2011, 43, pp. 1249 1256. 
[9] Bueno,M., González-Jorge, H., Martínez-Sánchez, J., Díaz-Vilariño, L., Arias, P.: "Evaluation of point cloud registration using Monte Carlo method", Measurement, 2016, 92, pp. $264-270$.

[10] Lichti, D. D., Stewart, M. P., Tsakiri, M., Snow, A. J.: "Benchmark tests on a three dimensional laser scanning system", Geomatics Res. Austral., 2000, pp. 1 - 23.

[11] Lichti, D. D.: "Terrestrial laser scanner self calibration: correlation sources and their mitigation”, ISPRS J. Photogramm., 2010, 65, pp. 93 - 102.

[12] González-Aguilera, D., Rodríguez-Gonzálvez, P., Armesto, J., Arias, P.: “Trimble GX200 and Riegl LMS-Z390i sensor self-calibration”. Opt. Express, 2011, 19(3), pp. 26762693.

[13] Amiri Parian, J., Grün, A.: "Integrated laser scanner and intensity image calibration and accuracy assessment”, Int. Arch. Photogramm. Remote Sens. Spat. Inf. Sci., 2005, XXXVI(3), pp. $18-23$.

[14] Lichti, D. D., Jamtsho, S.: "Angular resolution of terrestrial laser scanners", The Photogrammetric Record, 2006, 21(114), pp. 141 - 160.

[15] Boehler, W., Bordas Vincent, M., Marbs, A.: "Investigating laser scanner accuracy", The International Arch. Photogramm., Remote Sens. Spat. Inf. Sci., 2003, XXXIV(5), pp. 696 -701 .

[16] Gordon, S., Lichti, D. D., Stewart, M., Tsakiri, M.: "Metric performance of a highresolution laser scanner", Proc. SPIE, 2001, 4309, pp. $174-184$.

[17] Soudarissanane, S., Lindenbergh, R., Menenti, M., Teunissen, P: "Scanning geometry: influencing factor on the quality of Terrestrial Laser Scanning points", ISPRS J: Photogram. Remote Sens., 2011, 66(4), pp. $389-399$.

[18] Mechelke, K., Kersten, T. P., Lindstaedt, M.: "Comparative investigations into the accuracy behavior of the new generation of terrestrial laser scanning systems", Proc. Conf. Opt. 3D Meas. Tech., 2007, pp. $319-327$. 
[19] González-Jorge, H., Rodríguez-Gonzalvez, P., González-Aguilera, D., VarelaGonzález, M.: "Metrological comparison of terrestrial laser scanning systems Riegl LMS Z390i and Trimble GX”, Opt. Eng., 2011, 50(11), pp. $1162011-10$.

[20] Puente, I., González-Jorge, H., Riveiro, B., Arias, P.: “Accuracy verification of the Lynx Mobile Mapper system”, Opt. Laser Technol., 2013, 45, pp. 578 - 586.

[21] González-Jorge, H., Riveiro, B., Vázquez-Fernández, E., Martínez-Sánchez, J., Arias, P.: "Metrological evaluation of Microsoft Kinect and Asus Xtion sensors", Measurement, 2013, 46, pp. $1800-1806$.

[22] González-Jorge, H., Rodríguez-Gonzálvez, R., Martínez-Sánchez, J., GonzálezAguilera, D., Arias, P., Gesto, M., Díaz-Vilariño, L.: “Metrological comparison between Kinect I and Kinect II sensors", Measurement, 2015, 70, pp. 21 - 26.

[23] Bueno, M., Díaz-Vilariño, L., Martínez-Sánchez, J., González-Jorge, H., Lorenzo, H.: "Metrological evaluation of KinectFusion and its comparison with Microsoft Kinect sensor", Measurement, 2015, 73, pp. $137-145$.

[24] Faro Focus 330X datasheet: http://www.faro.com/products/3d-surveying/laser-scannerfaro-focus-3d/features

[25] Riegl LMS Z390i datasheet: http://www.riegl.com/uploads/tx_pxpriegldownloads/10_DataSheet_Z390i_20-04-2010.pdf

[26] Faro Photon 80 datasheet: http://archive.cyark.org/temp/FAROphoton8020datasheet.pdf

[27] Trimble GX datasheet: https://ismar.eplica.is/media/landmaelingar/3dscanner/022543148A_GX_3Dscanner_DS 0206_lr.pdf

[28] Faro Focus 3D datasheet:

http://www.faro.com/products/3d-surveying/laser-scanner-faro-focus-3d/features

[29] Leica C10 Scanstation hatasheet: https:/hds.leicageosystems.com/downloads123/hds/hds/ScanStation\%20C10/brochuresdatasheet/Leica_ScanStation_C10_DS_en.pdf 
[30] BQ Witbox 3D printing machine: https://www.bq.com/es/witbox-2

[31] Hexagon Metrology Absolute Arm: http://www.hexagonmetrology.es/ROMERAbsolute-Arm 791.htm

[32] Cloud Compare Software tool: http://cloudcompare.org/ 
Table 1. Technical specifications of terrestrial laser scanning systems.

\begin{tabular}{|c|c|c|c|c|c|c|}
\hline & Faro Focus 330X & Riegl LMS Z390i & Faro Photon 80 & Trimble GX & $\begin{array}{l}\text { Faro Focus 3D } \\
\end{array}$ & Leica C10 \\
\hline University & UVigo & UVigo & Usal & Usal & Usal & TU Delft \\
\hline $\begin{array}{l}\text { Measurement } \\
\text { principle }\end{array}$ & PS & ToF & PS & $\mathrm{ToF}$ & PS & ToF \\
\hline $\begin{array}{l}\text { Max. range } \\
\text { (m) }\end{array}$ & 330 & 400 & 76 & $200 / 350$ & 120 & 300 \\
\hline $\begin{array}{l}\text { Pulse } \\
\text { repetition } \\
\text { rate }(\mathrm{pts} / \mathrm{s})\end{array}$ & 976,000 & 11,000 & 120,000 & 5,000 & 976,000 & 50,000 \\
\hline $\begin{array}{l}\text { Range error } \\
(\mathrm{mm})\end{array}$ & 2@25m & $6 @ 50 \mathrm{~m}$ & 2@25m & 7@100m & $2 @ 25 \mathrm{~m}$ & 4@50m \\
\hline $\begin{array}{l}\text { Wavelength } \\
(\mathrm{nm})\end{array}$ & 1550 & 1540 & 785 & 532 & 905 & 532 \\
\hline $\begin{array}{l}\text { Beam } \\
\text { divergence }\left(^{\circ}\right)\end{array}$ & 0.011 & 0.017 & 0.009 & --- & 0.011 & 0.006 \\
\hline \multirow{2}{*}{$\begin{array}{l}\text { Field of view } \\
\left({ }^{\circ}\right)\end{array}$} & $300 \mathrm{~V}$ & $80 \mathrm{~V}$ & $320 \mathrm{~V}$ & $60 \mathrm{~V}$ & $305 \mathrm{~V}$ & $270 \mathrm{~V}$ \\
\hline & $360 \mathrm{H}$ & $360 \mathrm{H}$ & $360 \mathrm{H}$ & $360 \mathrm{H}$ & $360 \mathrm{H}$ & $360 \mathrm{H}$ \\
\hline \multirow[t]{2}{*}{ Step width $\left(^{\circ}\right)$} & $0.009 \mathrm{~V}$ & $0.002 \mathrm{~V}$ & $0.009 \mathrm{~V}$ & $0.0003 \mathrm{~V}$ & $0.009 \mathrm{H}$ & $0.0003 \mathrm{~V}$ \\
\hline & $0.009 \mathrm{H}$ & $0.002 \mathrm{H}$ & $0.008 \mathrm{H}$ & $0.0004 \mathrm{H}$ & $0.009 \mathrm{~V}$ & $0.0003 \mathrm{H}$ \\
\hline Weight (kg) & 5.2 & 15 & 14.5 & 13 & 5 & 13 \\
\hline
\end{tabular}


Table 2. Nominal lengths of the step hight.

\begin{tabular}{cc}
\hline \hline Planes & Length (m) \\
\hline \hline$V 1-V 2$ & 0.05 \\
\hline$V 1-V 3$ & 0.10 \\
\hline$V 1-V 4$ & 0.15 \\
\hline$V 1-V 5$ & 0.20 \\
\hline$H 1-H 2$ & 0.04 \\
\hline$H 1-H 3$ & 0.07 \\
\hline$H 1-H 4$ & 0.09 \\
\hline$H 1-H 5$ & 0.10 \\
\hline \hline
\end{tabular}


Table 3. Technical specifications of the Hexagon Metrology absolute arm 7325SI.

\begin{tabular}{|c|c|}
\hline \multicolumn{2}{|l|}{ 7-axis arm } \\
\hline Measuring range $(\mathrm{m})$ & 2.5 \\
\hline Probing point repeatability $(\mathrm{mm})$ & 0.049 \\
\hline Probing volumetric accuracy (mm) & 0.069 \\
\hline Scanning system accuracy (mm) & 0.084 \\
\hline \multicolumn{2}{|c|}{ Integrated scanner RS2 } \\
\hline Max. point acquisition rate (points/s) & 50,000 \\
\hline Line width $(\mathrm{mm})$ & 65 \\
\hline Points per line & 1,000 \\
\hline Line frequency $(\mathrm{Hz})$ & 50 \\
\hline Min. point spacing (mm) & 0.046 \\
\hline Expanded precision $(k=2)(\mathrm{mm})$ & 0.030 \\
\hline \multicolumn{2}{|c|}{ Certificate of traceable calibration (ASME B89.22-2004) } \\
\hline Point repeatability achieved ( $\mathrm{mm}$ ) & 0.017 \\
\hline Length accuracy achieved (mm) & 0.022 \\
\hline \multicolumn{2}{|c|}{ "Scanning system verification report (Sphere 80\%) } \\
\hline Max. $(\mathrm{mm})$ & 0.0233 \\
\hline Standard deviation (mm) & 0.0167 \\
\hline Diameter deviation (mm) & 0.0310 \\
\hline
\end{tabular}

\section{Figure captions}


Fig. 1. Physical artifact made with spheres.

Fig. 2. Physical artifact based on step height. Planes are marked by $H$ and $V$ labels.

Fig. 3. Point cloud from the physical artifact based on spheres.

Fig. 4. Point cloud from the physical artifact based on step height.

Fig. 5. Error $\Delta D_{S}$ in the evaluation of the distance between the center of spheres versus the measurement range $R$. The physical artifact is positioned in horizontal position.

Fig. 6. Error $\Delta D_{S}$ in the evaluation of the distance between the center of spheres versus the measurement range $R$. The physical artifact is positioned in vertical position.

Fig. 7. Error $\Delta D p$ in the evaluation of the distance between the horizontal planes of the standard artifact. Range is fixed to $10 \mathrm{~m}$. 


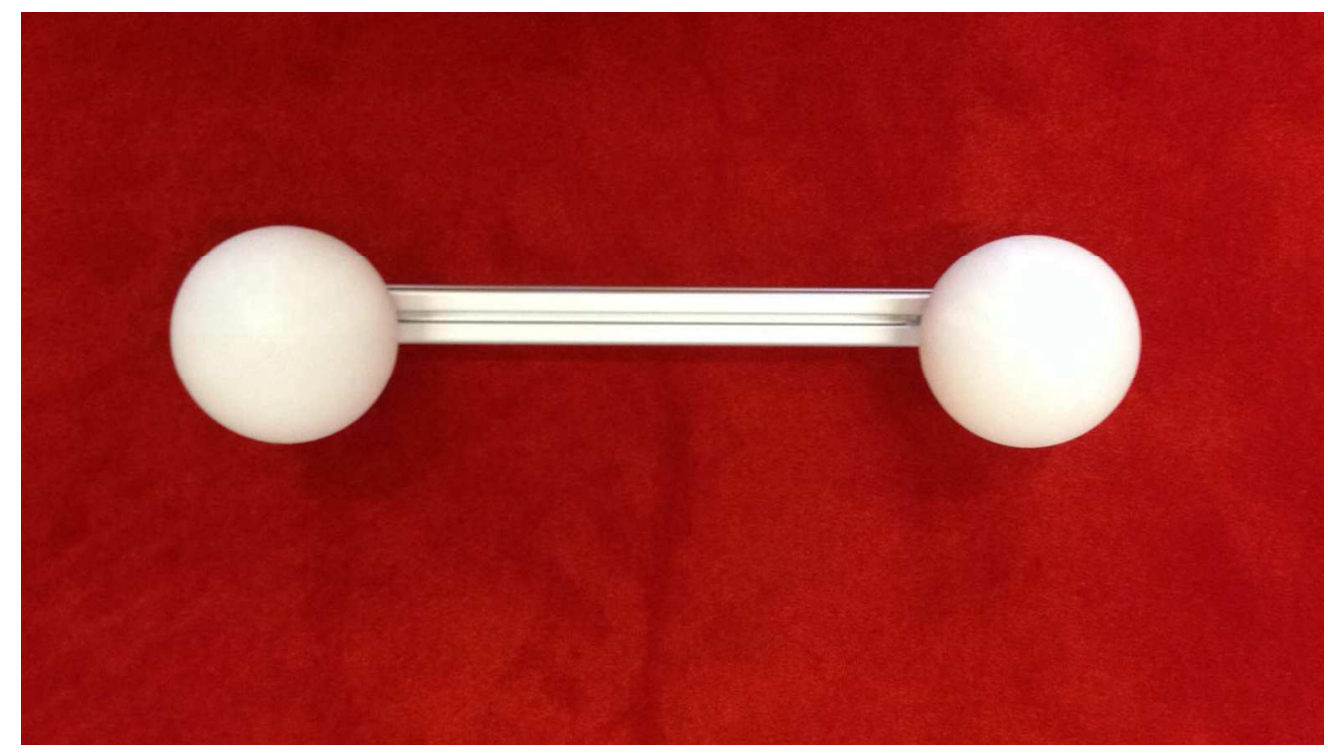

Fig. 1. Physical artifact made with spheres. $135 \times 76 \mathrm{~mm}(300 \times 300 \mathrm{DPI})$ 


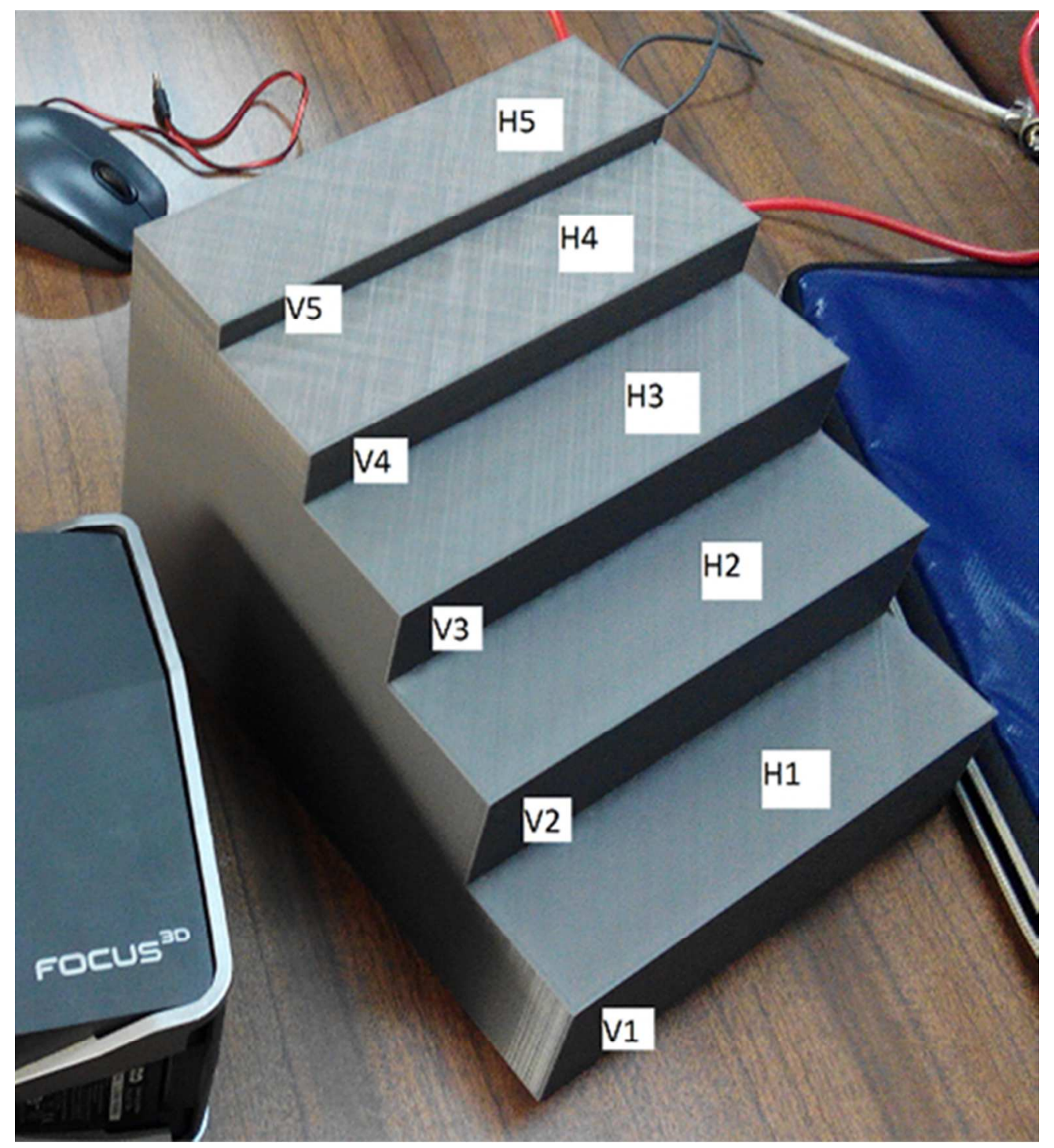

Fig. 2. Physical artifact based on step height. Planes are marked by $\mathrm{H}$ and $\mathrm{V}$ labels.

$48 \times 53 \mathrm{~mm}(300 \times 300 \mathrm{DPI})$ 


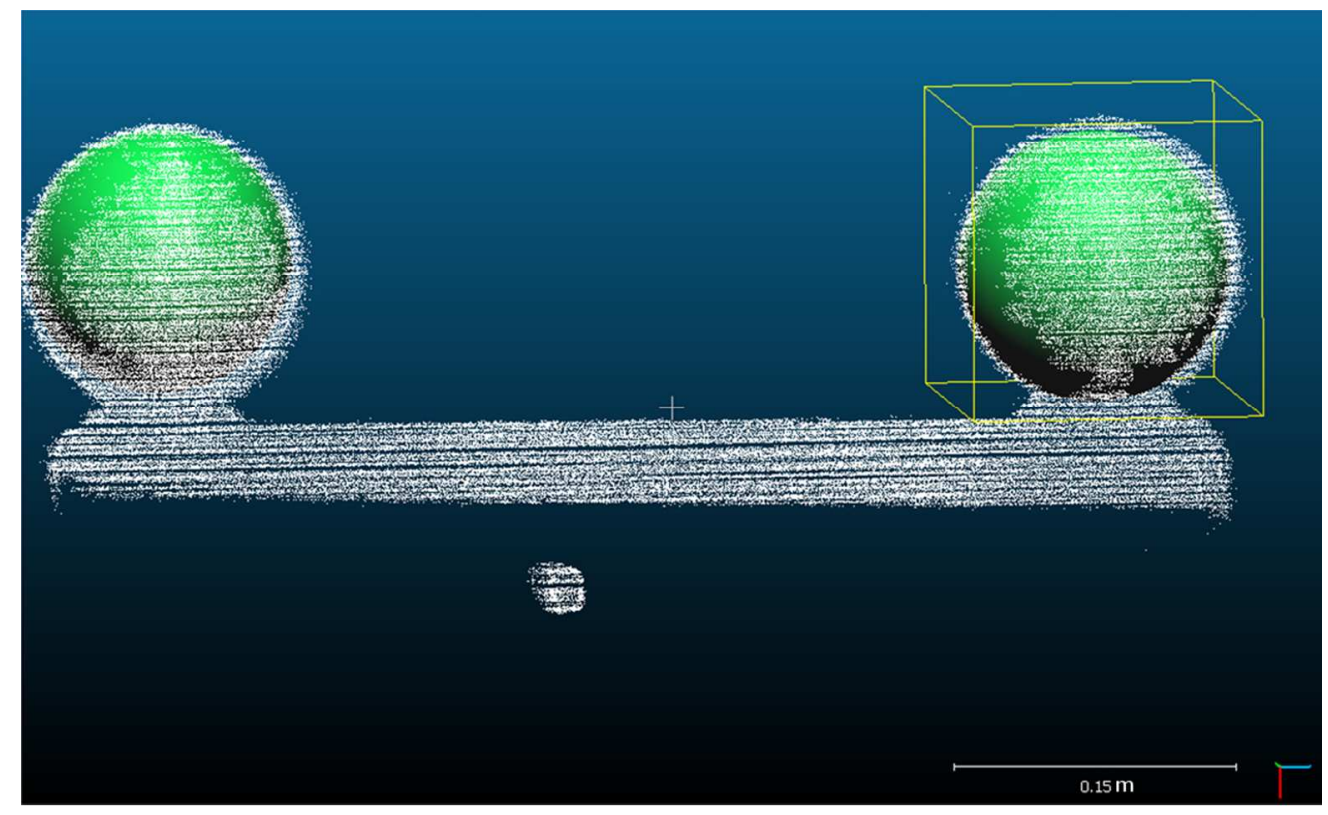

Fig. 3. Point cloud from the physical artifact based on spheres.

$92 \times 56 \mathrm{~mm}(300 \times 300 \mathrm{DPI})$ 


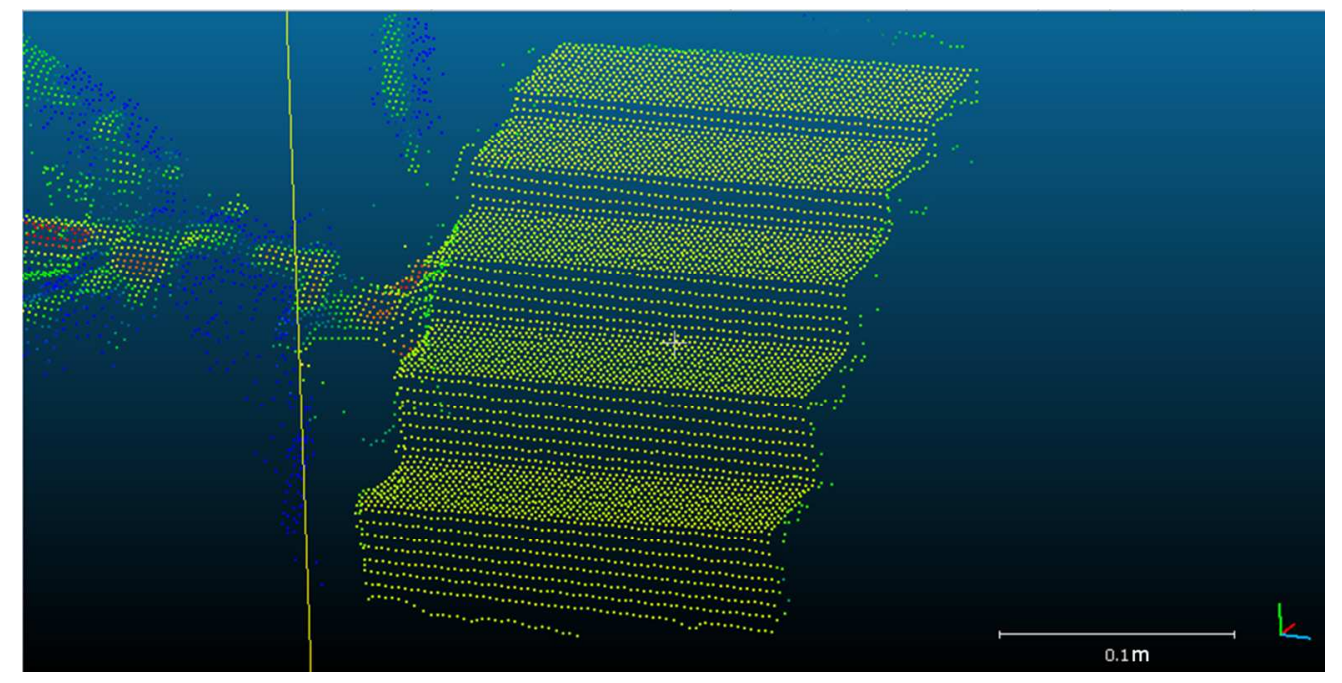

Fig. 4. Point cloud from the physical artifact based on step height.

$97 \times 49 \mathrm{~mm}(300 \times 300 \mathrm{DPI})$ 


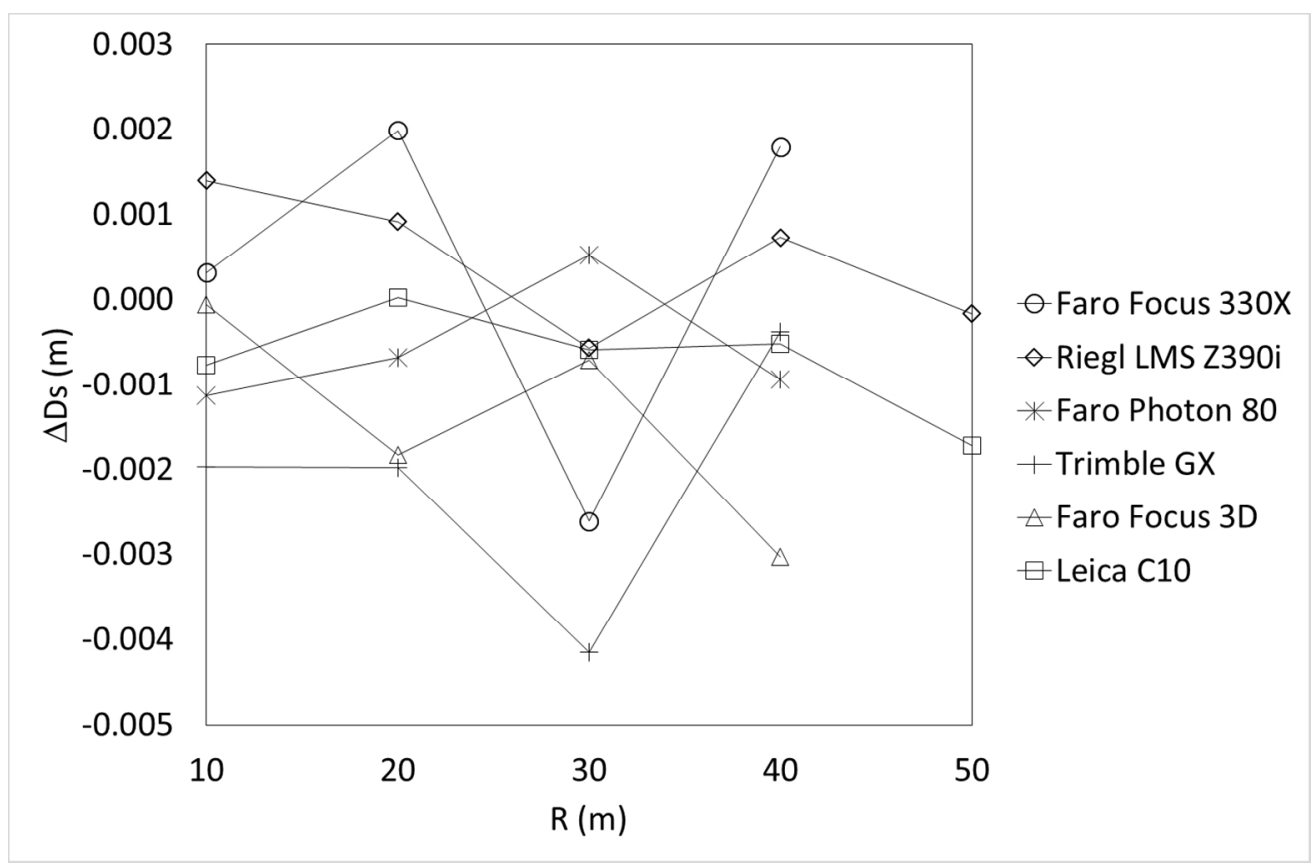

Fig. 5. Error $\Delta \mathrm{Ds}$ in the evaluation of the distance between the center of spheres versus the measurement range $R$. The physical artifact is positioned in horizontal position.

$$
129 \times 84 \mathrm{~mm}(300 \times 300 \mathrm{DPI})
$$




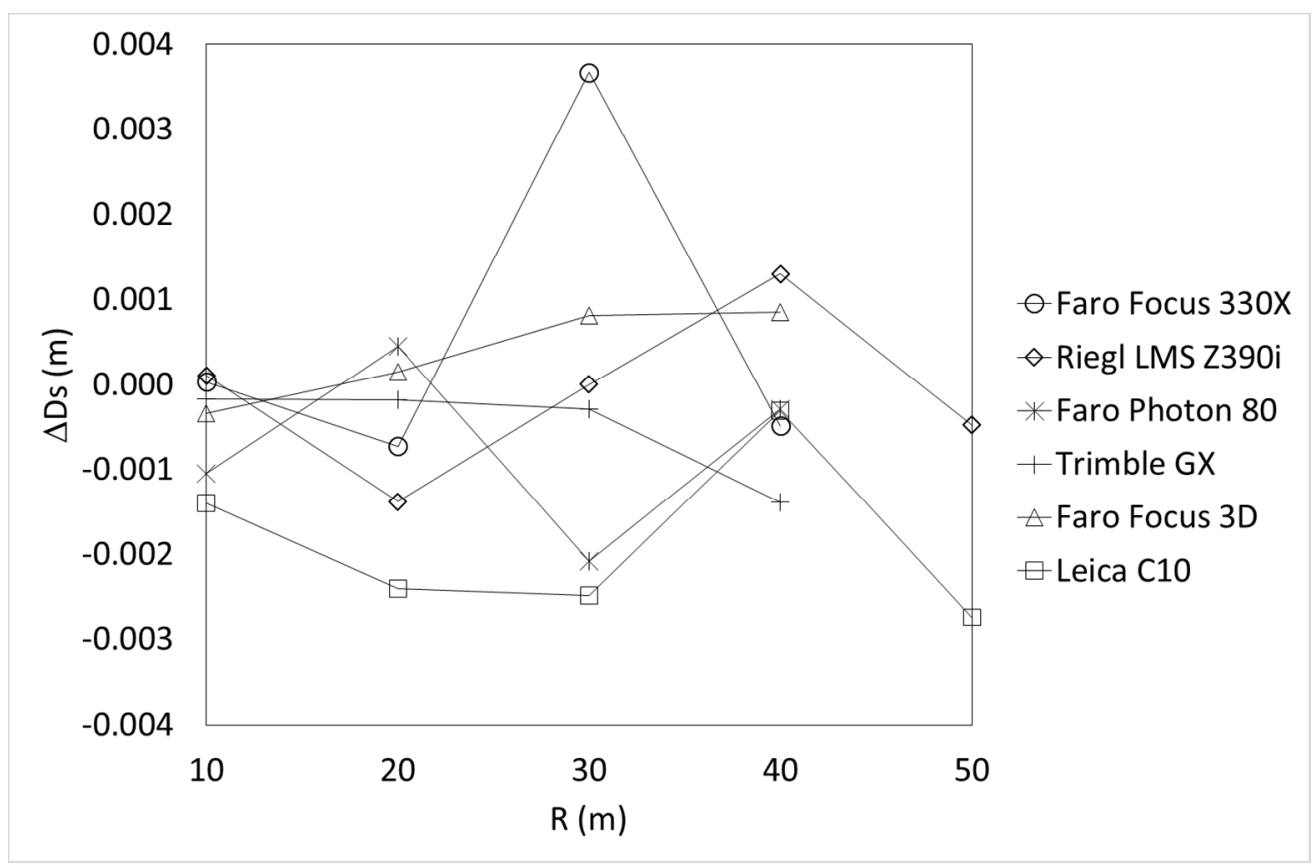

Fig. 6. Error $\Delta \mathrm{Ds}$ in the evaluation of the distance between the center of spheres versus the measurement range $R$. The physical artifact is positioned in vertical position.

$$
129 \times 84 \mathrm{~mm}(300 \times 300 \mathrm{DPI})
$$




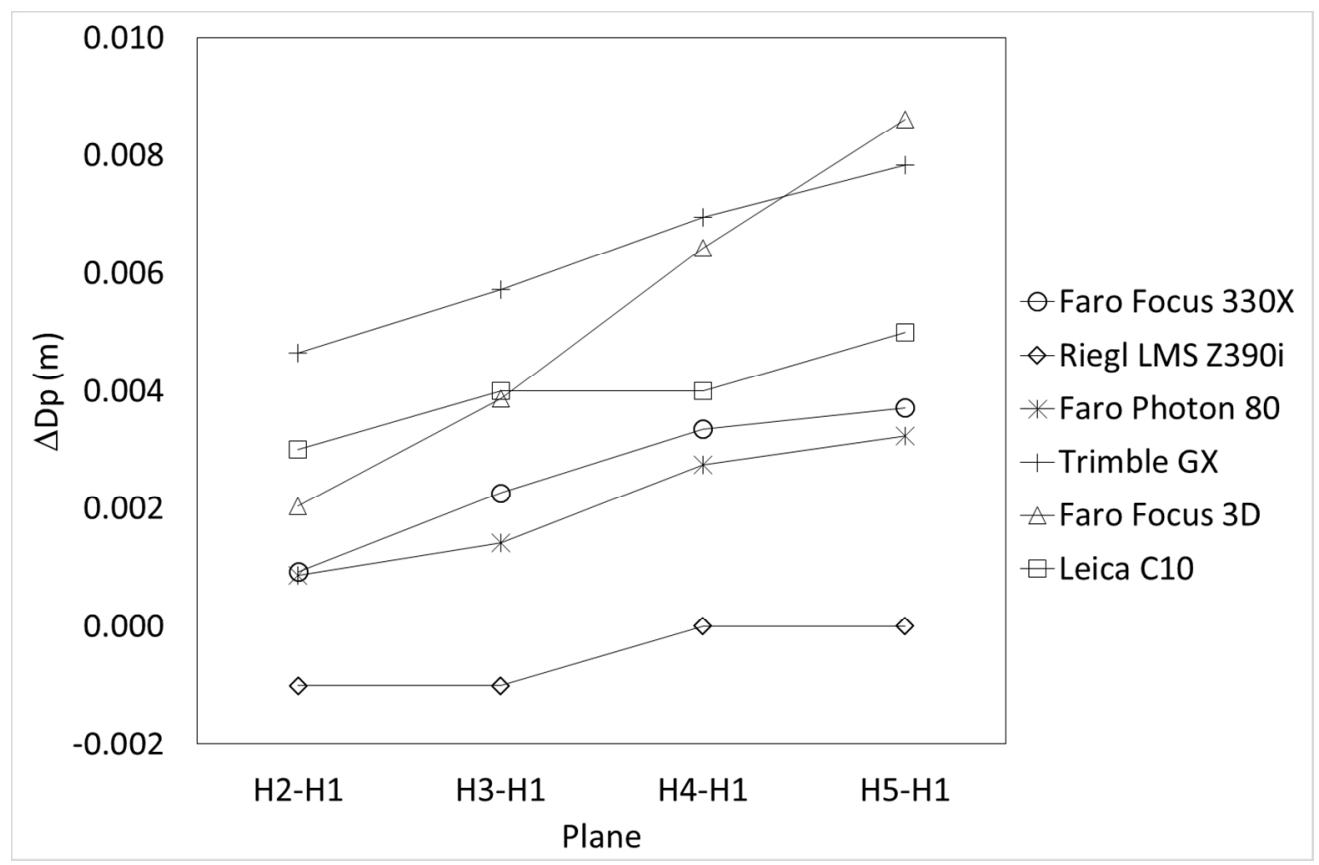

Fig. 7. Error $\Delta \mathrm{Dp}$ in the evaluation of the distance between the horizontal planes of the standard artifact. Range is fixed to $10 \mathrm{~m}$.

$129 \times 84 \mathrm{~mm}(300 \times 300 \mathrm{DPI})$ 